future to be incorporated with the Proceedings and Transactions of the Liverpool Biological Society and not issued separately. The present report includes accounts of experimental lobster rearing by W. C. Smith, plaice marking in the Irish Sea by R. J. Daniel and R. A. Fleming, and a comparative study of the abdominal musculature in Malacostraca (Part III) by R. J. Daniel. This last paper is a continuation of Dr. Daniel's work on the muscles of various Crustacea which have been published in the Lancashire Sea-Fisheries Reports in 1927, 1929 and 1932, and describes the musculature of Lophogaster typicus and Gnathophausia zoëa. The weight of evidence shows a close affinity between the Euphausiacea and the lower decapods, although there are apparent similarities between Meganyctiphanes on one hand and Lophogaster, Gnathophausia and Praunus on the other. It is concluded by the author, after very careful consideration, that the former represents a true relationship (homology) and that similarities between mysids and euphausids are due to con. vergence. These researches on the abdominal muscles are carefully and beautifully worked out and are accompanied by fine drawings.

\section{Welfare Problems in India}

IMPENDING constitutional changes, which will affect welfare administration in India, add particular significance to two articles by Mr. Cedric Dover in the January issues of Mother and Child and the Quarterly Review. He discusses the organisation and condition of maternal and child welfare in India, and the needs and defects of welfare legislation. Maternal mortality rates are 4-20 times, and infant mortality rates 3-4 times as much as the averages obtaining in England, and are closely correlated with communal prosperity and housing conditions. An interesting biological correlation is that between climatic conditions and frequency of conceptions, the maximum number occurring in Bombay during the period of minimum humidity (January-April). Both articles emphasise the need for centralisation and greater co-ordination of welfare activities. A consolidated Public Health Act for all India is regarded as the primary essential of welfare legislation, and a commission on legal reform is suggested, which will recognise that "the main object of law is the prevention of dysgenic, and the encouragement and establishment of eugenic forces", unimpeded by traditional beliefs. The operation of Hindu, Mohammedan and Christian laws under one administration is dismissed as "an anachronism that needs no emphasis".

\section{Commercial Timbers of the Punjab}

A Forest Bulletin, No. 84, in the Economy Series of the Imperial Forest Research Institute, Dehra Dun, has been recently issued (Delhi: Manager of Publications, 1934) entitled the "Identification of the Commercial Timbers of the Punjab" by K. A. Chowdhury, wood technologist. The Indian Research Institute has been a pioneer in getting together information on the timbers of a definite region, having undertaken intensive research in the timber resources of India during the past twenty years; with the result that the number of timbers now sold in the market is much greater than it was a few years ago. This fact, states the author, has resulted in difficulties in identification of some of the species which have now come upon the market. The aim of the Bulletin, and a predecessor on Burma timbers, is primarily to show the differences of the anatomical structure of some of the more commercial timbers of the Punjab, and the way to identify them on the spot with the assistance only of a hand lens and pocket knife. Brief notes are also given on the strengths, seasoning properties, durability, working qualities and uses for each species : these latter add greatly to the practical value of the publication. The commercial woods of the Punjab, of which a proportion are temperate species, both conifer and broad-leaved species, are comparatively few in number and their identification is by no means difficult. Those who make use of this Bulletin will find the excellent low power $(\times 10)$ photomicrographs of considerable assistance. The species dealt with include the Himalayan conifers, deodar, spruce and silver firs, several pines and broad-leaved trees such as walnut, several oaks, boxwood, poplar and alder; and the Plains species, such as sál, mango, tun, sissoo, tamarix and so forth.

\section{Chemical Research in Czechoslovakia}

UNINFLUENCED by the economic depression, which has been felt in Central Europe as keenly as elsewhere, the various schools of chemical research in Czechoslovakia have continued their activities with undiminished energy, as is apparent from the papers published in vol. 6 of the Collection of Czechoslovak Chemical Communications. In inorganic chemistry, Dr. Skramovsky's 'stathmographic apparatus' has found further application in the study of complex inorganic salts such as the bismuth oxalates. The apparatus automatically records photographically the change in weight of a substance with, for example, increasing temperature. Striking dehydration curves have been obtained and results are found to vary according to well-defined circumstances. Thus copper sulphate crystals from aqueous solutions show quite different behaviour from those from alcoholic solutions. Further, inoculation with lower hydrated salt causes characteristic changes in the curves photographically recorded. The stathmographic method thus seems to promise a new field of investigation in inorganic chemistry. In physical chemistry, the Prague polaro. graphic school has published further work especially in connexion with the catalytic evolution of hydrogen at the dropping mercury cathode, which can be made use of in micro-analytical tests. Revenda's work in Prof. Heyrovský's laboratory has extended the applicability of polarographic analysis to the anions. In organic chemistry, the Collection includes results of researches by Prof. Votoček and his collaborators on new conversions of sugars to furane compounds. New glucosyl-alkyl-amines are described, and the constitution of fuco-hexonic and rhodeo-hexonic acids has been worked out. 